\title{
The Possibility of Using Adhesive for Bonding Steel with Ceramics
}

\author{
Ivan Jandrlić ${ }^{1, *}$, Stoja Rešković ${ }^{1}$, Tin Brlić ${ }^{1}$, Damir Hršak ${ }^{1}$ \\ University of Zagreb Faculty of Metallurgy, Aleja narodnih heroja 3, 44103 Sisak, Croatia
}

\begin{abstract}
Nowadays many different systems use elements that are constructed from different materials. There are various solutions for joining different kinds of materials into one part. Whether we are talking about mechanical or adhesive bonding, both types of joints have their advantages and disadvantages. In certain cases, preference is given to the adhesive bonding. It is primarily from the inability of constructing a mechanical connection, or the possibility of cracking due to the technical nature of the mechanical joints. Such case occurred when a ceramic cylinder was needed to be connected to the metal spindle. This paper presents determination of the strength of the glued joint for three different adhesives, and for the specific type of joint. Tested adhesives were of chemical type; modified acrylic ester, and two component epoxy adhesive. Tests were performed by measuring the largest tensile load that the joint can withstand without loosening or fracture.
\end{abstract}

Keywords: steel-to-ceramic bonded joints; adhesive joint; static behavior; epoxy adhesive.

\section{Introduction}

Components made from different types of materials are increasingly used today when making various assemblies. This is especially common in assemblies and constructions where steel parts are used, all in order to reduce the overall mass. On the other hand, different materials have different properties and when combined together they make parts of the assemblies that possess the best properties of each material component separately. The problem with the construction and fabrication of such parts is an adequate connection between different materials. So far a mechanical connection has been commonly used, however, depending on the type of load and the design of the circuit itself, mechanical joints may be a weak spot [1-2]. At the same time, often it is not possible to carry out the mechanical connection between different components due to mechanical nature of the joint. The advancement of bonding technology and making more reliable adhesives has led to the more frequent use of adhesives, in order to provide the reliable and adequate bonds between different materials in various assemblies [3-6].

In this specific case, during production, there was a part of the assembly that uses horizontally mounted cylinders and pistons. Within those cylinders, the steel pistons compress a chemically relatively aggressive medium. Existing steel pistons had a relatively short service life due to the presence of the corrosive agent and continuous wear during production. So the idea was to change material used for pistons, and it was decided to go with $\mathrm{Al}_{2} \mathrm{O}_{3}$ ceramics. The specific characteristics of $\mathrm{Al}_{2} \mathrm{O}_{3}$ ceramics have shown that this would be an adequate material for the existing problem. However, the imposed problem was how to connect the ceramic piston with a rod that was supposed to stay out of steel. Due to the narrow space, and the possibility of crack formation over time, it was not possible to perform a classical 
mechanical connection between the parts. For this reason, it was decided to carry out the connection by using adhesives as a bonding agent. From existing commercially available adhesives, three of them were selected to test them for this purpose. One was one component modified acrylic ester, and two of them were two component epoxy adhesives.

The second question that came up was how to test the strength of the ceramic-steel joint. Testing of the adhesive properties is well documented in the literature [3-7]. There are a number of testing methods depending on the purpose and type of load during the exploitation of the bonded joints. Due to the specificity of available testing equipment and required demands on joints, it was decided to carry on a static tensile test on samples that were specifically designed for this case.

The aim of this study is to determine which of the selected adhesives is most suitable for this specific use. The results of the study are not to emphasize the deficiencies of the tested adhesives, but to rather point out the most suitable one for this particular case. During testing, it was a goal to determine the maximum force which the adhesive joint can withstand without loosening or fracture.

\section{Experimental Section}

The strength of the ceramic-steel joint was tested using a static tensile test. A tensile testing machine with a maximum load of $50 \mathrm{kN}$ was used. Various models for testing the adhesive properties of glue are available in the literature $[3,4,8,9]$. Due to the specific type of joint, it was concluded that conventional testing methods of joints would not give the complete information on the strength of the presented joint. Therefore, samples were made equal to the shape and dimensions of the pieces to be used in the assembly during production, Fig. 1.

Due to the specific shape of grips on testing machine, samples were constructed in such way that steel inserts were placed on both sides of the ceramic part, Fig. 1 a). Dimensions of the steel inserts, Fig. 1 b), that will be joint with the ceramic cylinder, were made in the same dimension as the connecting rood that which will be later used. Doing so, it was possible to conduct two parallel tests simultaneously. The steel inserts were made from structural steel, while the central ceramic part was made out of $\mathrm{Al}_{2} \mathrm{O}_{3}$ ceramics.

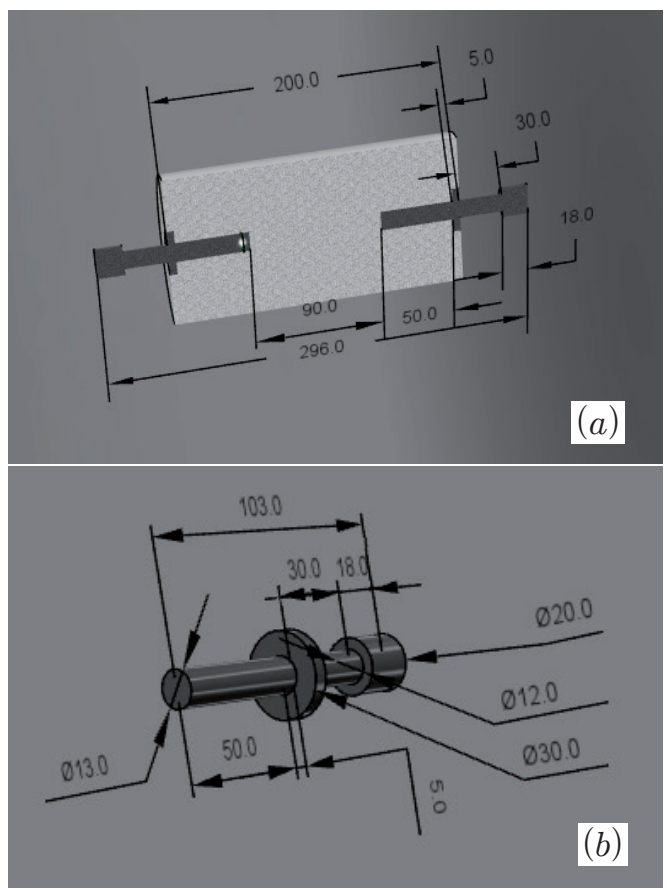

Fig. 1: Dimensions of samples for adhesive tests: a) Mounted parts on ceramic cylinder. b) Steel part to be inserted and bonded to the ceramic cylinder.

Three adhesives were selected for testing. All three tested adhesives, according to their data sheets, show a high strength of joint, ability to fill gaps, good performance at elevated temperatures and high chemical resistance when fully cured. Selected adhesives were:

1. Sample - One component Modified acrylic ester LOCTITE 312

2. Sample - Two component epoxy adhesive Loctite Hysol 3430

3. Sample - Two component epoxy adhesive Araldite ${ }^{\circledast}$ AV 138M-1 / Hardener HV 998-1

All three selected adhesives are for the typical purpose of gluing different materials, such as metals, glass, and ceramics. Joining of samples and curing of adhesive was carried out according to the manufacturer's instructions, taking into account the thickness of the adhesive layer, curing time and the surface preparation. After the minimum time required for curing, samples were kept for 6 hours at constant ambient temperature prior to the test. Samples are placed in tensile testing machine grips, Fig. 2, and the load was gradually increased.

The test was carried out at a low displacement speed of $3 \mathrm{~mm} / \mathrm{min}$, since testing speed may affect 
the measurement results $[9,10]$. The samples were stretched up to the point of the first appearance of separation between the steel insert and ceramic cylinder.

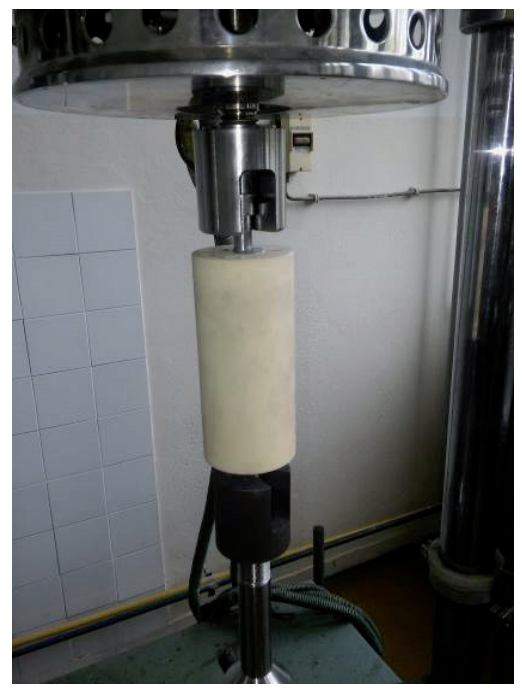

Fig. 2: Sample in grips before testing.

\section{Risk-based Thinking modeling}

After the required time for adhesives curing, prescribed by the manufacturer, samples were inspected and it was established that the samples were ready for further testing, Fig. 3.

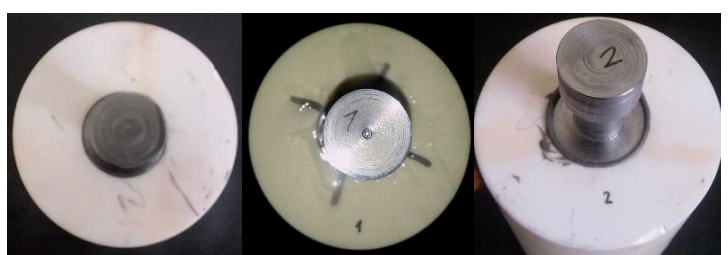

(a)

(b)

(c)

Fig. 3: (a) Modified acrylic ester LOCTITE 312. (b) Loctite Hysol 3430. (c) Araldite ${ }^{\circledR}$ AV 138M-1/Hardener HV 998-1.

From the preliminary examination of the glued samples, except in color, there is no significant difference between the used adhesives, Fig. 3. Samples were subjected to the tensile load, and the maximum force was recorded to capture the point at which the separation of the glued joint would occur.

In the case of modified acrylic ester LOCTITE 312, the first separation of glued joint occurred at a load of 12.964 N. Separation was first observed on the upper part of the sample, Fig. 4 a), followed by failure of joint in the lower part, Fig. 4 b).

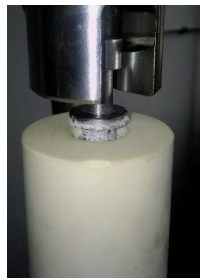

(a)

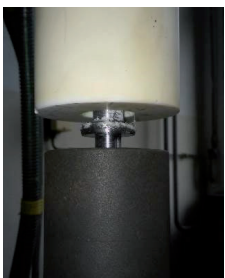

(b)

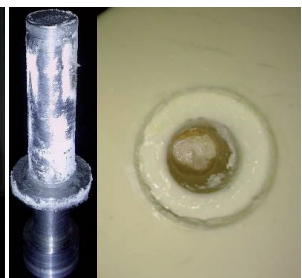

(c)
Fig. 4: Separation of the glued joint in case of modified acrylic ester. (a) Top part of the sample. (b) The bottom part of the sample. (c) Inside of the cylinder with still wet glue.

Subsequent detailed examination of the joint showed that the adhesive was not completely cured. This is particularly expressed in the inner parts of both ceramic cylinders, Fig. 4c). Since the metal inserts were made with close tolerances to the ceramic cylinder, it is logical assumption that this has been due to poor contact of the adhesive with the air. For this reason, curing of adhesive has not been completely carried out throughout the whole joint, resulting in a poor bonding between the ceramic and steel insert.

In the case of two-component epoxy Loctite Hysol 3430 adhesive, also came to the separation of the ceramic-steel joint. In this case, the separation occurred at the load of $31,550 \mathrm{~N}$. Similarly to the first case, the separation was first observed in the upper part of the sample, followed by the failure in the lower part, Fig. 5.

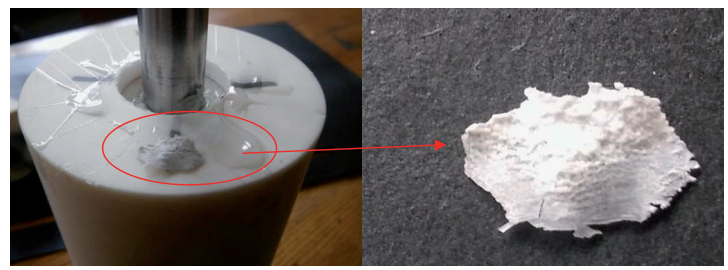

Fig. 5: Detachment of joint in case of Loctite Hysol 3430 (right), and chipped off adhesive (left).

By subsequent inspection of failure, it was found out that in this case curing was finished and it was uniform through the whole ceramic-metal joint. In this case, it was observed a particular chip that braked of the sample, Fig. 5. At first, it seemed as it was the thin layer of ceramics that had been separated from the cylinder. The closer examination showed it to be a part of adhesive that was drawn out from the cylinder during the pulling of the steel 
insert from it.

In the case of testing sample bonded with two component epoxy adhesive Araldite ${ }^{\circledast}$ AV 138M1 / Hardener HV 998-1, the test was carried out in the same way as in the previous two cases. There was no detachment of ceramics - steel joint during testing. The test was conducted up to the point when the maximum possible load of $50.000 \mathrm{~N}$ was reached. In the subsequent detailed examination of the ceramics - steel joint it was not observed any weakening or failure of the joint. Therefore it was concluded that the adhesive used in this case is most appropriate for this specific case of joining the ceramic with steel.

\section{Conclusions}

Study has shown that there were some differences in the strength of the ceramics - steel joints achieved with the three tested adhesives. Although all three tested adhesives sustained weary high amounts of stress, only one showed it can withstand the maximum load of $50 \mathrm{kN}$.

So, from this, we concluded that for this specific case for bonding ceramics with steel, the best joint was accomplished by using the two-component epoxy adhesive Araldite ${ }^{\oplus}$ AV $138 \mathrm{M}-1$ with Hardener HV 998-1. This assumption was based on the fact that there were non-observable changes in ceramics - steel joint during testing.

We founded that in the case when there is no sufficient contact with the air, as in this type of joint, there is a possibility that adhesive will not cure to the end, regardless giving it more than enough curing time.

\section{References and Notes}

[1] Uday, M.B.; Ahmad-Fauzi M.N.; Noor A. M.; Rajoo, S., (2016). Chapter 8: Current Issues and Problems in the Joining of Ceramic to Metal. Editor Mahadzir Ishak. Joining Technologies. InTech, Chapters published September 21, 2016 under CC BY 3.0 license, 282 pages.

[2] Kweon Jin-Hwe; Jung, Jae-Woo; Kim, Tae-Hwan; Choi, JinHo; Kim, Dong-Hyun, Failure of carbon composite-to-aluminum joints with combined mechanical fastening and adhesive bonding, (2006), Composite Structures, vol. 75, p. 192-198

[3] Ciupack, Y; Pasternak, H; Mette, C; Stammen, E; Dilger, K. (2017) Adhesive bonding in steel construction - Challenge and innovation, Procedia Engineering, vol. 172 , p. 186 - 193

[4] Hulimka, J; Kałuża, M. (2017) Preliminary tests of steel-to- steel adhesive joints, Procedia Engineering, vol. 172 , p. 385 $-392$

[5] Pasternak, H; Schwarzlos, A; Schimmack, N. (2004), The application of adhesives to connect steel members, Journal of Constructional Steel Research, vol. 60, p. 649-658

[6] Huntsman Advanced Materials, Users Guide to Adhesives, from: https://www.freemansupply.com/datasheets/adhesivesguide.pdf, date of access: 10.3.2018.

[7] FINAT - European association, ADHESIVE PROPERTIES AND TESTING METHODS (according to FINAT regulation) from http://www.adestor.com/en-US/Pages/DescargaDocu. aspx?ref=\%2012\&lib=4, date of access: 13.3.2018.

[8] Jeandrau, J. P; Peyrac, C; Lefebvre, F; Renard, J; Gantchenko, V; Patamaprohm,B; Guinault, C. (2015), Procedia Engineering, vol. 133, p. $508-517$

[9] Müller, M; Valášek, P; Ruggiero, A; D'Amato, R. (2016), Research on influence of loading speed of structural twocomponent epoxy adhesives on adhesive bond strength, Procedia Engineering, vol. 149, p. 340 - 345

[10] Blackman, B. R. K.; Cooper, V. ; Ivankovic A.; Karac, A.; Kinloch, A. J.; Rodriguez Sanchez, S.; Teo, W. S. , (2011) Modeling the fracture behaviour of adhesively-bonded joints as a function of test rate, Engineering Fracture Mechanics, vol. 78, p. 973-989

\section{Biographical notes}

Ivan Jandrlić, asst. professor, (born in 1985.) works as assistant professor at the University of Zagreb Faculty of Metallurgy, Department of Mechanical Metallurgy, Laboratory of Deformation Metal Processing. He graduated from the Faculty of Metallurgy in 2009. His research areas are metal testing using destructive and nondestructive testing methods, metal working technologies and investigation of deformation zone. He is an author/co-author on numerous publications published in journals and conferences.

Professor Stoja Rešković, (born in 1954.) works at the University of Zagreb Faculty of Metallurgy, Laboratory of Deformation Metal Processing. Her research areas are metal testing, metal deformation design, micro-alloyed steels, rolling strips and pipes and research of the interdependence of strengthening and softening mechanisms in hot and cold deformation. She is an author/co-author on numerous publications published in journals and conferences.

Tin Brlić, assistant, (born in 1988) works as assistant at the University of Zagreb Faculty of Metallurgy, Department of Mechanical Metallurgy, Laboratory of Deformation Metal Processing. He graduated from the Faculty of Metallurgy in 2013 and Faculty of Chemical Engineering and Technology in 2014. His research areas are plastic deformation, materials testing with different methods especially with thermography and digital image correlation, metal working technologies and quality management. He is a member of the Council of technical area, University of Zagreb. 